\title{
A systematic literature review of personalized learning terms
}

\author{
Atikah Shemshack ${ }^{*}$ (i) and Jonathan Michael Spector
}

\author{
* Correspondence: \\ atikahshemshack@my.unt.edu \\ University of North Texas, Denton, \\ USA
}

\begin{abstract}
Learning is a natural human activity that is shaped by personal experiences, cognitive awareness, personal bias, opinions, cultural background, and environment. Learning has been defined as a stable and persistent change in what a person knows and can do. Learning is formed through an individual's interactions, including the conveyance of knowledge and skills from others and experiences. So, learning is a personalized experience that allows one to expand their knowledge, perspective, skills, and understanding. Therefore, personalized learning models can help to meet individual needs and goals. Furthermore, to personalize the learning experience, technology integration can play a crucial role. This paper provides a review of the recent research literature on personalized learning as technology is changing how learning can be effectively personalized. The emphasis is on the terms used to characterize learning as those can suggest a framework for personalized and will eventually be used in meta-analyses of research on personalized learning, which is beyond the scope of this paper.
\end{abstract}

Keywords: Personalized learning, Adaptive learning, Learning, Intelligent tutoring systems, Learning analytics, Personalized adaptive learning, Systematic review

\section{Introduction}

Personalized learning has been a topic of research for a long time. However, around 2008, personalized learning started to draw more attention and take on a transformed meaning as seen in Fig. 1. However, we believe the variety of terms that have been used for personalized learning seems to be an obstacle to the progress of personalized learning theories and research. Although there exists an abundance of the resources/ studies on personalized learning, not having a readily agreed-upon term of personalized learning might be the obstacle in research progress on personalized learning. In response to this need, this paper is focused on analyzing the terms that have been used for personalized learning. A distinctly personalized learning approach can help the educational researchers to build up research on previous data, instead of trying to start new research from scratch each time. This paper will present a research-based framework for personalized learning and discuss future research directions, issues, and challenges through an in-depth analysis of the definitions and terms used for personalized learning.

(c) The Author(s). 2020 Open Access This article is licensed under a Creative Commons Attribution 4.0 International License, which permits use, sharing, adaptation, distribution and reproduction in any medium or format, as long as you give appropriate credit to the original author(s) and the source, provide a link to the Creative Commons licence, and indicate if changes were made. The images or other third party material in this article are included in the article's Creative Commons licence, unless indicated otherwise in a credit line to the material. If material is not included in the article's Creative Commons licence and your intended use is not permitted by statutory regulation or exceeds the permitted use, you will need to obtain permission directly from the copyright holder. To view a copy of this licence, visit http://creativecommons.org/licenses/by/4.0/. 


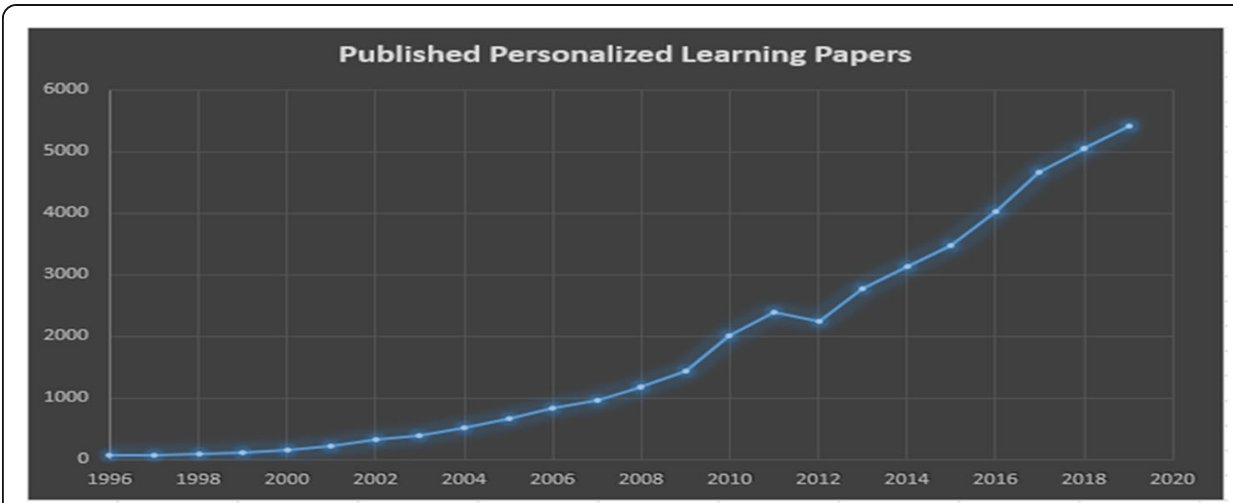

Fig. 1 The number of published papers on "personalized learning"

Personalized learning has existed for hundreds of years in the form of apprenticeship and mentoring. As educational technologies began to mature in the last half of the previous century, personalized learning took the form of intelligent tutoring systems. In this century, big data and learning analytics are poised to transform personalized learning once again. Learning has been characterized as a stable and persistent change in what a person knows and can do (Spector, 2015). Personalized learning is a complex activity approach that is the product of self-organization (Chatti, 2010; Miliband, 2006) or learning and customized instruction that considers individual needs and goals. Personalized learning can be an efficient approach that can increase motivation, engagement and understanding (Pontual Falcão, e Peres, Sales de Morais and da Silva Oliveira, 2018), maximizing learner satisfaction, learning efficiency, and learning effectiveness (Gómez, Zervas, Sampson and Fabregat, 2014). However, while such personalized learning is now possible, it remains as one of the biggest challenges in modern educational systems. In this paper a review of progress in personalized learning using current technologies is provided. The emphasis is on the characteristics of personalized learning that need to be taken into consideration to have a well-developed concept of personalized learning.

We started with the definition of personalized learning suggested by Spector (2014, 2018) and others that are discussed below, which requires a digital learning environment to be classified as a personalized learning environment to be adaptive to individual knowledge, experience and interests and to be effective and efficient in supporting and promoting desired learning outcomes. These characteristics are those which are typically discussed in the research community although we found it challenging to find a sufficient number of published cases that reported effect sizes and details of the sample in order to conduct a formal meta-analysis. Lacking those cases suggests that personalized learning in the digital era is still in its infancy. As a result, we conducted a more informal albeit systematic review of published research on personalized learning.

Furthermore, we, along with many educational technologists, believe an efficient personalized learning approach can increase learners' motivation and engagement in learning activities so that improved learning results. While that outcome now seems achievable, it remains a largely unrealized opportunity according to this research review. Truong (2016) stated that providing the same content to students with different qualifications and personal traits and having different interests and needs is not 
considered adequate anymore when learning can now be personalized. Miliband (2006, as cited in Lee, Huh, Lin and Reigeluth, 2018) promoted personalized learning to be the solution to tailoring the learning according to individuals' needs and prior experience so as to allow everyone to reach their maximum potential through customized instruction (Hsieh and Chen, 2016; Lin, Yeh, Hung and Chang, 2013).The customized instruction that includes what is taught, how it is taught, and the pace at which it is taught. This allows learning to meet individual needs, interests and circumstances which can be quite diverse (Brusilovsky and Peylo, 2003; Liu and Yu, 2011). Furthermore, FitzGerald et al. (2018) pointed out the personalization of learning is now a recurring trend across government agencies, popular media, conferences, research papers, and technological innovations.

Personalized learning is in demand (Huang, Liang, Su and Chen, 2012) due to new technologies involving big data and learning analytics. It should be tailored to and continuously modified to an individual learner's conditions, abilities, preferences, background knowledge, interests, and goals and adaptable to the learner's evolving skills and knowledge (Sampson, Karagiannidis and Kinshuk, 2002; Sharples, 2000). Today's personalized learning theories are inspired by educational philosophy from the progressive era in the previous century, especially John Dewey's $(1915,1998)$ emphasis on experiential, learner-centered learning, social learning, extension of the curriculum, and fitting for a changing world. McCombs and Whisler (1997; as cited in Lee et al., 2018) claimed that a learner-centered environment develops as it considers learners' unique characteristics using the best knowledge of teaching and learning which are available. Furthermore, Lockspeiser and Kaul (2016) claimed that individualized learning is a tool to facilitate learnercentered education. FitzGerald et al. (2018) pointed out that personalization is a crucial topic of current interest in technology-oriented learning design and discussion for government policymakers, but less so in educational research. This might be a good explanation of disunity of personalized learning approaches.

On the other hand, Niknam and Thulasiraman (2020) argued that educational society has been interested in having a personalized learning system that adjusts the pedagogy, curriculum, and learning environment for learners to meet their learning needs and preferences. A personalized learning system can adapt itself when providing learning support to different learners to defeat the weakness of one-size-fits-all approaches in technology-enabled learning systems. The goal is to have a learning system that can dynamically adapt itself based on a learner's characteristics and needs to provide personalized learning. Human one-on-one tutors can do this and now it is possible for digital systems to do so as well. Schmid and Petko (2019) pointed out that a look at international research literature shows that personalized learning is a multilayered construct with numerous definitions and various forms of implementation. Which supports our claim that one of the most critical problems with personalized learning is, there is no readily agreed-upon meaning of the phrase 'personalized learning'. Schmid and Petko (2019) supported this claim by stating that a clearly defined concept of personalized learning is still lacking; instead, it serves as an umbrella term for educational strategies that try to do justice to the individual's abilities, knowledge, and learning needs of each student. Spector (2013) claimed that there would be more robust information to support personalized learning as technology develops. So many different terms have been 
used in the replacement of 'personalized learning'. Researchers could not locate a systematic literature review on personalized learning terms that review the terms that have been used for personalized learning, and it is important to address this need. Therefore, this review was done to close that gap and respond to the need for a unified, personalized learning term. As a result, personalized learning definitions and the terms that have been used interchangeably, such as adaptive learning, individualized instruction, and customized learning are analyzed in this paper. These terms were chosen because they have been most used in the education field (Reisman, 2014). In the next several sections, each term will be defined, and their relationship with personalized learning will be discussed. The analysis of these terms guided the systematic review of the research literature that follows.

\section{Adaptive learning}

Most educators recognize the advantages of adaptive learning, but evidence-based research stays limited as adaptive learning is still evolving (Liu, McKelroy, Corliss and Carrigan, 2017). Adaptive learning is one of the terms that has been used interchangeably with personalized learning. The adaptive learning system is built on principles that have been around for a very long time dating back to the era of apprenticeship training and human tutoring. However, many other labels such as individualized instruction, self-paced instruction, and personalized instruction were used interchangeably while trying to produce the most suitable sequence of learning units for each learner (GarciaCabot, De-Marcos and Garcia-Lopez, 2015; Reisman, 2014). While early forms of adaptive learning (e.g., apprenticeship training and human tutoring) only dealt with one or a very small number of learners, the current interest is using adaptive learning for large numbers of learners, which is why there is such interest in big data and learning analytics.

For instance, adaptive learning has been interchangeably used by Yang, Hwang and Yang (2013) in their study that focused on the development of adaptive learning by considering students' preferences (Dwivedi and Bharadwaj, 2013) and characteristics, including learning styles (Çakıroğlu, 2014; Klašnja-Milićević, Vesin, Ivanović and Budimac, 2011) and cognitive styles (Lo, Chan and Yeh, 2012) which concluded to be effective. Wang and Liao (2011) defined adaptive learning as a developed system (Lu, Chang, Kinshuk, Huang and Chen, 2014) to accommodate a variety of individual differences (Scheiter et al., 2019; Wang \& Liao, 2011) such as gender, learning motivation, cognitive type, and learning style to determine optimal adaptive learning experience that accommodates a variety of individual differences (Afini Normadhi et al., 2019) to remove barriers of time and location. Griff and Matter (2013) discussed that adaptive learning is also referred to as computer-based learning, adaptive educational hypermedia, and intelligent tutoring. Furthermore, Hooshyar, Ahmad, Yousefi, Yusop and Horng (2015) used personalized and adaptive learning to explain the importance of the Intelligent Tutoring System (Aeiad and Meziane, 2019) for implementing one-to-one personalized and adaptive teaching. "Although the terms 'personalized learning' and 'adaptive learning' are different, they are often used interchangeably in various studies" (Aroyo et al., 2006; Göbel et al., 2010; Gómez et al., 2014; Lin et al., 2013, as cited in Xie, Chu, Hwang and Wang, 2019, p.2). 
Based on this review, adaptive learning systems are defined as those that are computerized learning systems that adapt learning content, presentation styles, or learning paths based on individual students' profiles, learning status, or human factors (Chen, Liu and Chang, 2006; Tseng et al., 2008; Yang et al., 2013).

\section{Individualized instruction}

Individualized instruction is one of the terms that are often used to talk about the specific needs and goals of individuals to be addressed during instruction. U.S. Department of Education (2010) defined personalized learning as involving customizing the learning pace to individual learners (individualization), tailoring instructional methods (differentiation), and personalizing learning content. This notion has evolved from one-on-one human tutoring. It is not agreed upon whether individualization is a component of personalized learning or another term that can be used in place of personalized learning. The review results show that instead of being a component, individualized instruction has been used as a replacement term for personalized learning and is a product of personalized learning. Chatti, Jarke and Specht (2010) and Chou, Lai, Chao, Lan and Chen (2015) had used both terms without defining/explaining how they relate to each other. Bahçeci and Gürol (2016) created a portal that offers individualized learning content based on the individual's level of cognitive knowledge. Bahçeci and Gürol (2016) stated that education should be done by recognizing the individual differences of the students such as students learning styles (Çakıroğlu, 2014; Klašnja-Milićević et al., 2011) and characteristics. The researchers observed that Bahçeci and Gürol (2016) used individualized learning and personalized learning interchangeably without pointing out that they were doing so.

Also, most individualized learning studies have used individualized instruction to refer to IEP (individualized educational plans) for students with disabilities to accommodate their needs and goals. Even though individualized instruction is suggested as an approach that individualize material to improve the learning experience for students with learning disabilities, it can benefit all students (Barrio et al., 2017; Ko, Chiang, Lin and Chen, 2011). Personalized learning considers students' interests, needs, readiness, and motivation and adapts to their progress by situating the learner at the center of the learning process. Individualized learning allows for individualization of learning based on the learner's unique needs (Cavanagh, 2014; Lockspeiser \& Kaul, 2016). While a learner-centered paradigm of education has influenced personalized learning, the current teacher-student ratios in school systems seem to be an obstacle to make learning experiences personalized for individual students without technology (Lee et al., 2018), with the exception of the requirement for IEPs in many school districts. We follow the definition offered by the U.S. Department of Education and note that individualized learning in school systems requires significant technology support, such as big data and learning analytics.

\section{Customized learning}

While Lee et al. (2018) suggested a learner-centered system that supports diverse needs and development of individual learners' potentials. This system develops customized instructional methods and learning content for individual learners with unique 
characteristics and interests. Lee et al. (2018) suggested that learner-centered learning and personalized learning are blended and considered together. Lee et al. (2018) defined a personalized learning plan (PLP) that refers to a customized instructional plan (Somyürek, 2015) that considers individual differences and needs, characteristics, interests, and academic mastery. The PLP includes the notions of individualization, differentiation, and personalization that allows learning to be personally relevant, engaging, appropriate to the learners' capabilities, and respectful of individual differences, making learning useful and motivational.

The review of those three terms reveals a great deal of overlap with an emphasis on the need to use technology to support such efforts. This study reviews definitions of personalized learning terms used in research papers from 2010 to 2020 by systematically reviewing the literature to compare the similarities and differences in definitions of each of these terms. The hope is to synthesize the terms used for personalized learning so the researchers can analyze and go through the research in the field and conduct meta-analyses and syntheses of the research literature. Also, analyzing the definitions of the term 'personalized learning', 'adaptive learning', 'individualized instruction', and 'customized learning' that have been used can help to develop a unified definition for personalized learning that can lead a framework. The framework can help with having a common understanding of personalized learning rather than a collection of loosely defined systems. A unified description of personalized learning and analyzing the studies related to personalized learning can help consolidate findings and suggest new areas to explore.

Our idea of personalized learning rests on the foundation that humans learn through experience and by constructing knowledge. Constructivism claims that learners' acquired knowledge and understanding, determine learning ability and that knowledge acquisition is a process of construction according to individuals' experience (Ormrod, 2011). Personalized learning is influenced by a learner's prior experiences, backgrounds, interests, needs, goals, and motivation. Moreover, it is accomplished via meaningful interactions in individual learners' lives. Furthermore, no conscious effort is needed to be actively learning while engaged in everyday life (Kinshuk, 2012) although reflection and mega-cognition can promote learning.

Adaptive instruction, blended instruction, differentiation, customized instruction, individualized learning, adaptive learning, proactive supports, real-world connections, and applications are hallmarks of good personalized learning. In general, personalized-learning models seek to adapt to the pace of learning and the instructional strategies, content and activities being used to fit best each learner's strengths, weaknesses, and interests. Personalized learning is about giving students some control over their learning (Benhamdi, Babouri and Chiky, 2017; Jung, Kim, Yoon, Park and Oakley, 2019; Tomberg, Laanpere, Ley and Normak, 2013), differentiating instruction for each learner, and providing real-time individualized feedback to teachers and learners (Nedungadi and Raman, 2012), which is all effortlessly blended throughout the learning activity. Putting a framework together can help with a practical personalized learning model for all. The model can be developed and evolved as technology develops and we learn more about human learning and machine learning. 


\section{Research methodology}

For this review, the guidelines published by Okoli to conducting a systematic literature review for Information Systems Research were adapted (Okoli, 2015). Okoli's work provides a detailed framework for writing a systematic literature review with its roots in information technology. As this systematic literature review is rooted in information technology, it was deemed appropriate to use Okoli's work as the basis for this body of work.

Okoli presented eight significant steps that need to be followed to conduct a scientifically, rigorous systematic literature review. These steps are listed below:

1. Identify the purpose: The researchers identified the purpose and intended goals of the study to ensure the review is clear to readers.

2. Draft protocol and train the team: Reviewers agreed on procedures to follow to ensure consistency in how they complete the review.

3. Apply practical inclusion screen: Reviewers were specific about what studies they considered for review and which ones they eliminated without further examination. The reviewers created four phases to review papers to produce the final papers to review.

4. Search for literature: Reviewers described the literature search details and justified how they ensured the search's comprehensiveness.

5. Extract data: After reviewers identified all the studies to be included in the review, they systematically extract the applicable information from each study by going through four review phases they explained in search query.

6. Appraise quality: The reviewers explicitly listed the criteria used to decide which papers they will exclude for insufficient quality in the search query. Researchers reviewed all papers and decided on final papers after explicit four search phases. They finalized the papers to be reviewed, depending on the content of the papers' content and quality.

7. Synthesize studies: The researchers analyzed the data obtained from the studies using appropriate qualitative techniques.

8. Write the review: The process of a systematic literature review was explicitly described in adequate detail that other researchers can independently reproduce the review's results.

\section{Research question}

This literature review promotes research around personalized learning in informational education. To fulfill answer of "What are the similarities and differences of different terms used for personalized learning approaches?” we need a research base and theoretical framework that provides answers to basic questions. Furthermore, the following questions are sub-questions to be considered during the study.

1. How is personalized learning defined?

2. How adaptive learning has been used and how it relates to personalized learning?

3. How individualized instruction has been used and how it relates to personalized learning? 
4. How is customized learning connected to personalized learning?

5. What components need to be included in a well-defined personalized learning term?

Also, researchers are seeking a unified definition of personalized learning that will include all those different components. That is the focus of this literature review was conducted.

\section{Sources of literature}

To answer the research question, the researchers have selected the following well known and reputable databases to base this literature review: Scopus, Science Direct, EBSCOhost, IEEE Xplore, JSTOR, and Web of Science to ensure all related journals of the field are included. The most relevant journals for the systematic review were chosen consistently from these databases. Also, Google Scholar h5-index for the category "Educational technology" was used as the starting point since this category is a specific category for personalized learning studies.

Databases in which to base this literature review are listed in Table 1.

The top nine journals from the "Educational Technology" category from google scholar h5-index selected to keep the range of the papers manageable while trying to ensure the review is broad enough to include enough studies that can satisfactorily answer the research question. Later, most of the journals about educational technology were indexed. SJR (SCIMAGO JOURNAL RANK) was used to validate the impact of the selected journals. Even though the impact factor is not perfectly aligned with Google Scholar's h5-index order, the selected journals listed the most impactful journals in the educational technology field. Also, even though Journal of Learning Analytics was listed on google scholar and showed having a high impact on education technology, researchers have not located any qualified paper according to selection procedures, thus this journal was eliminated from review.

This review solely retrieved peer-reviewed article papers from online journals because those online academic journals are known to be reliable and authoritative. They allow the readers to verify the facts from their sources, which increases the reliability of enriched studies filled with data and facts. They enable the readers to perform comprehensive research and allow the reader to access more data without the limitations of space and time. A defined method was set in this research for selecting journals, to keep the process methodologically reliable and scientifically consistent. The researchers review the main databases for educational technology to ensure all related journals of the field are included. This review is only focused on journals to keep the scope of the review manageable and provide reviewed data to create a resource for future studies.

Journals in which to base this literature review are listed in Table 2.

\section{Supplementary procedures}

Relevant papers were initially identified through traditional searches of online databases and journals. These papers were subsequently analyzed to determine their applicability to the study. 
Table 1 The search results for "personalized learning" for selected databases

\begin{tabular}{|c|c|c|}
\hline $\begin{array}{l}\text { Database } \\
\text { name }\end{array}$ & $\begin{array}{l}\text { \# Results for initial search on } \\
\text { "personalized learning" }\end{array}$ & Main journals listed (\#journal articles) \\
\hline \multirow[t]{8}{*}{ EBSCOhost } & \multirow[t]{8}{*}{4372} & - Computers \& Education (130) \\
\hline & & $\begin{array}{l}\text { - Journal of Educational Technology \& Society } \\
\text { (72) }\end{array}$ \\
\hline & & $\begin{array}{l}\text { - Educational Technology Research and } \\
\text { Development (53) }\end{array}$ \\
\hline & & - Interactive Learning Environments (48) \\
\hline & & - Computers in Human Behavior (43) \\
\hline & & $\begin{array}{l}\text { - International Journal of Emerging Technologies } \\
\text { in Learning (36) }\end{array}$ \\
\hline & & • British Journal of Educational Technology (33) \\
\hline & & - Journal of Computer Assisted Learning (33) \\
\hline \multirow[t]{5}{*}{ Scopus } & \multirow[t]{5}{*}{1826} & - Computers and Education (18) \\
\hline & & - Computers in Human Behavior (10) \\
\hline & & $\begin{array}{l}\text { - Educational Technology Research and } \\
\text { Development (10) }\end{array}$ \\
\hline & & - Education and Information Technologies (9) \\
\hline & & - Interactive Learning Environments (8) \\
\hline \multirow{4}{*}{$\begin{array}{l}\text { Science } \\
\text { Direct }\end{array}$} & \multirow[t]{4}{*}{796} & - Computers and Education (121) \\
\hline & & - Procedia-Social and Behavioral Science (80) \\
\hline & & - Computers in Human Behavior (68) \\
\hline & & - Procedia Computer Science (58) \\
\hline \multirow[t]{5}{*}{$\begin{array}{l}\text { Web of } \\
\text { Science }\end{array}$} & \multirow[t]{5}{*}{451} & $\begin{array}{l}\text { - International Journal of Emerging Technologies } \\
\text { in Learning (30) }\end{array}$ \\
\hline & & - Computers Education (18) \\
\hline & & • Educational Technology Society (16) \\
\hline & & - Computers in Human Behavior (10) \\
\hline & & $\begin{array}{l}\text { - Educational Technology Research and } \\
\text { Development (10) }\end{array}$ \\
\hline \multirow[t]{5}{*}{ IEEE Xplore } & \multirow[t]{5}{*}{426} & - Conference Proceedings (398) \\
\hline & & - IEEE Access (7) \\
\hline & & - IEEE Transactions on Learning Technologies (4) \\
\hline & & • IBM Journal of Research and Development (2) \\
\hline & & $\begin{array}{l}\text { - IEEE Transactions on Emerging Topics in } \\
\text { Computing (2) }\end{array}$ \\
\hline \multirow[t]{3}{*}{ JSTOR } & \multirow[t]{3}{*}{241} & - Educational Technology \& Society (102) \\
\hline & & - Educational Technology (32) \\
\hline & & $\begin{array}{l}\text { - Educational Technology Research and } \\
\text { Development (29) }\end{array}$ \\
\hline
\end{tabular}

\section{Search query}

An appropriate search query was formulated that would find relevant personalized learning papers. The search query was as follows: (Publication Title: ("journal name")) AND ("term") and the journals listed in the table were searched for each of following terms: "personalized learning", "adaptive learning", "individualized instruction", and "customized learning." 
Table 2 The google scholar h5-index and journal impact for selected journals

\begin{tabular}{lll}
\hline Journal Name & $\begin{array}{l}\text { The google scholar } \\
\text { h5-index \& list order }\end{array}$ & $\begin{array}{l}\text { Journal impact factor } \\
\text { according to SJR }\end{array}$ \\
\hline Computers \& Education & $1-94$ & 2.323 \\
British Journal of Educational Technology & $2-56$ & 1.419 \\
The International Review of Research in Open and Distributed & $3-54$ & 1.202 \\
Learning & & 3.307 \\
The Internet and Higher Education & $4-50$ & 1.085 \\
Journal of Educational Technology \& Society & $5-49$ & 1.072 \\
*Journal of Learning Analytics & $6-36$ & 1.382 \\
Journal of Computer Assisted Learning & $7-34$ & 0.598 \\
Education and Information Technologies & $8-34$ & 0.98 \\
Educational Technology Research and Development & $9-34$ &
\end{tabular}

*Even though Journal of Learning Analytics was listed on google scholar and showed having a high impact on education technology, researchers have not located any qualified paper according to selection procedures, thus this journal was eliminated from review

\section{Inclusion/exclusion criteria}

Four phases were determined to meet the paper's inclusion criteria in the final set to be reviewed. First phase was initial search, searching each term 'personalized learning,' 'adaptive learning,' 'individualized instruction,' 'customized learning,' filtered years to 2010-2020 to review personalized learning papers which has been a hot topic for the research and policymakers. The language was filtered to English only to not wait on translation, the paper addressed technology integration, and type of the paper research articles that published in one of the peer-reviewed scientific journals listed to keep the scope manageable. The second search phase was eliminating by title, reviewing the abstract and keywords; researchers went through titles, abstracts, and keywords of each result of the initial search and included the ones look related to the term.

The next search phase, reading the abstract of each paper of the second search result-set, looking for a definition to see if it mentions the definition and/or terms that have been used for the term and the paper was available at one of the free online databases or the researchers' university library. The fourth step was to download all those papers to Mendeley (indexing database) and index them under sub-folders for each journal database. Then the entire paper was read to determine if the paper was to be included in the literature review by looking for components and definitions of personalized learning and star the ones to be included in the review. Each paper that met the inclusion criteria was read in its entirety a second time to validate the paper's decision in the final data set.

An initial search on google scholar on 'personalized learning' shows that the number of published papers on personalized learning has progressively increased year by year; especially there is a jump in 2008 as seen in Fig. 1. The date range of 2010 to the present day was chosen as this when personalized learning term started to gain more attention to research due to technology usage increase in education. The first smartphone was released in June 2007, which might be an element of the increase due to flexibility and access it provides. Cheung and Hew (2009) claimed that handheld devices are increasingly being used in educational settings. Primarily, papers published after the 2000s are focused on more technology-enhanced 
personalized learning. Figure 1 shows the results of the initial google scholar search on "personalized learning" published papers (Fig. 1).

\section{Results}

Nine journals were determined as the source of papers to be reviewed for this study. Each journal was searched for "personalized learning," "adaptive learning," "individualized instruction," "customized learning," and each result gone through the inclusion criteria and final phase; papers were saved in Mendeley under subfolders for each journal. Table 3 are search results for each phase by journals.

The title, abstract, and when necessary, the full paper was reviewed to decide if the paper met the inclusion criteria. This process helped to finalize the papers that will be used for this study, and the result set for "personalized learning" and the result set for each term to be reviewed is shown in Table 3. Some of the papers that did not fit the inclusion criteria are referenced in this paper as they provide valuable information about personalized learning. We reviewed 978 papers, and 4 phases of inclusion ended up with 56 relevant, high-quality papers. The 56 papers identified are marked in the references section with an asterisk. The systematic review methodology was used, and our literature search resulted in 56 relevant studies meeting the inclusion criteria. As shown in Table 4, 56 papers met the minimum quality criteria and were examined in detail; 33 of them use personalized learning, 17 adaptive learning, three individualized instruction, and three customized learning as the main term in the paper.

Our findings revealed that although so many terms are used in education settings, by policymakers and cooperate settings, in the research field, the terms used for personalized learning are unified, and mostly personalized learning and/or adaptive learning is being used. For example, Chatti et al. (2010) and Peng, Ma and Spector (2019) are the ones who put the two most common terms used for personalized learning together and started to use "personalized adaptive learning," which might be a good lead for future

Table 3 Result-set size for the number of papers of "personalized learning" during each research phase by the journal

\begin{tabular}{|c|c|c|c|c|}
\hline Journal Name & $\begin{array}{l}\text { Paper count - } \\
\text { initial search }\end{array}$ & $\begin{array}{l}\text { Paper count } \\
\text { - phase } 1\end{array}$ & $\begin{array}{l}\text { Paper count } \\
\text { - phase } 2\end{array}$ & $\begin{array}{l}\text { Final paper } \\
\text { count - phase } 3\end{array}$ \\
\hline 1. Computers \& Education & 121 & 32 & 10 & 9 \\
\hline $\begin{array}{l}\text { 2. British Journal of Educational } \\
\text { Technology }\end{array}$ & 82 & 6 & 3 & 1 \\
\hline $\begin{array}{l}\text { 3. The International Review of Research in } \\
\text { Open and Distributed Learning }\end{array}$ & 33 & 5 & 3 & 3 \\
\hline 4. The Internet and Higher Education & 11 & 1 & 1 & 0 \\
\hline $\begin{array}{l}\text { 5. Journal of Educational Technology \& } \\
\text { Society (ET\&S) }\end{array}$ & 102 & 18 & 6 & 6 \\
\hline 6. *Journal of Learning Analytics & 0 & 0 & 0 & 0 \\
\hline 7. Journal of Computer Assisted Learning & 35 & 7 & 3 & 3 \\
\hline $\begin{array}{l}\text { 8. Education and Information } \\
\text { Technologies }\end{array}$ & 91 & 25 & 8 & 8 \\
\hline $\begin{array}{l}\text { 9. Educational Technology Research, and } \\
\text { Development }\end{array}$ & 59 & 13 & 5 & 3 \\
\hline TOTAL & 534 & 107 & 38 & 33 \\
\hline
\end{tabular}

*Even though Journal of Learning Analytics was listed on google scholar and showed having a high impact on education technology, researchers have not located any qualified paper according to selection procedures, thus this journal was eliminated from review 
Table 4 Result-set size for the number of papers of "personalized learning," "adaptive learning," "individualized instruction," and "customized learning" by the journal

\begin{tabular}{|c|c|c|c|c|}
\hline Journal Name & $\begin{array}{l}\text { "Personalized } \\
\text { learning" }\end{array}$ & $\begin{array}{l}\text { "Adaptive } \\
\text { learning" }\end{array}$ & $\begin{array}{l}\text { "Individualized } \\
\text { instruction" }\end{array}$ & $\begin{array}{l}\text { "Customized } \\
\text { learning" }\end{array}$ \\
\hline 1. Computers \& Education & 9 & 6 & 0 & 0 \\
\hline 2. British Journal of Educational Technology & 1 & 4 & 0 & 0 \\
\hline $\begin{array}{l}\text { 3. The International Review of Research in Open } \\
\text { and Distributed Learning }\end{array}$ & 3 & 1 & 0 & 3 \\
\hline 4. The Internet and Higher Education & 0 & 0 & 0 & 0 \\
\hline $\begin{array}{l}\text { 5. Journal of Educational Technology \& Society } \\
\text { (ET\&S) }\end{array}$ & 6 & 3 & 2 & 0 \\
\hline $\begin{array}{l}\text { 6. International Conference on Learning Analytics } \\
\text { and Knowledge/Journal of Learning Analytics }\end{array}$ & 0 & 0 & 0 & 0 \\
\hline 7. Journal of Computer Assisted Learning & 3 & 0 & 0 & 0 \\
\hline 8. Education and Information Technologies & 8 & 2 & 0 & 0 \\
\hline $\begin{array}{l}\text { 9. Educational Technology Research, and } \\
\text { Development }\end{array}$ & 3 & 1 & 1 & 0 \\
\hline TOTAL: 56 & 33 & 17 & 3 & 3 \\
\hline
\end{tabular}

studies. However, future research needs to focus on components included in the personalized adaptive learning term's definition, and components are included in it. Chatti et al. (2010) and Peng et al. (2019) s paper put all together very well, and Peng et al. (2019) called it a personalized adaptive smart learning environment. Future studies can focus on what components are being used for each personalized learning approach and, at the same time, acknowledge it is a term that will evolve by time as we learn more about human learning and as technology develop. Table 4 shows the results of the searches for each term by journals.

\section{Existing and emerging trends}

Miliband (2006, as cited in Schmid \& Petko, 2019) pointed out that the Organisation for Economic Co-operation and Development OECD (2006) was among the first to use personalized learning term and described personalized learning in the report "Schooling for Tomorrow- Personalising Education" as a critical trend. According to this educational policy report, personalized learning is characterized by changes concerning five dimensions: assessment for learning by giving students individual feedback and setting suitable learning objectives, teaching and learning strategies based on the individual needs, curriculum choices (Tomberg et al., 2013), student-centered approach to school organization, and strong partnerships beyond the school.

According to the United States National Education Technology Plan 2017, personalized learning is defined as "instruction in which the pace of learning and the instructional approach are optimized for each learner's needs. Learning objectives, instructional strategies, and instructional content (Shute and Rahimi, 2017) may differ depending on learner needs. Besides, learning activities are meaningful and relevant to learners, driven by their interests, and often self-initiated." (p. 9).

American Psychological Association Presidential Task Force on Psychology in Education (1993, as cited in Lee et al., 2018) explained that a personalized learning plan (PLP) refers to a customized instructional plan that considers individual differences or needs such as career goals, characteristics, interests, and academic mastery. This 
includes the notions of individualization, differentiation, and personalization. Preparing and implementing PLPs allows for adjusting the pace to individual learners, adjusting instructional methods to individual characteristics, and having different learning goals tailored to individual interests. Furthermore, Sungkur, Antoaroo and Beeharry (2016) suggested an eye-tracking system to determine the user's interest and behavior. The PLPs allow learning to be personally relevant, engaging, appropriate to the learners' capabilities, and respectful of individual differences, making learning useful and motivational.

Learning analytics seems to grow to ensure the process of personalizing the content which allows mechanisms to identify student characteristics and associate them with a learning pattern (Ramos de Melo et al., 2014). Also, the ability to reactively organize personalized content may be a favorable factor in promoting the study support in virtual learning environments, respecting students' different individualities, preferences (Erümit and Çetin, 2020) and difficulty factors.

There is a research gap in an adaptive learning environment that needs to focus on emotions and personality which play a significant role in parts of adaptive systems, such as feedback (Fatahi, 2019). Furthermore, Junokas, Lindgren, Kang and Morphew (2018) created a system based on multimodal educational environments that integrate gesturerecognition systems and found that it is effective in improving the learning experience.

The personalization of learning has been achieved using various methods that have been made available by the rapid development of information communication technology (ICT) (Dawson, Heathcote and Poole, 2010). Furthermore, Ramos de Melo et al. (2014) stated that personalization is customizing the content that allows present parts of the content as needed by the student. That is one of the most common themes among most of the personalized learning approaches which can be done by using adaptive learning systems that can present personalized content for individual students (Hwang, Sung, Hung and Huang, 2013).

The higher-order thinking skills and communication had attracted little attention in terms of both learning outcomes and the process of adaptive/personalized learning due to the difficulty of measurement and the limited learning support types. Furthermore, virtual reality techniques might be a solution to this need. Developing learning approaches that build on students' current ability and support efficacy beliefs by allowing autonomy with a proper challenge to promote academic attainment (Foshee, Elliott and Atkinson, 2016; Xie et al., 2019). Future studies can focus on higher-order thinking skills cultivation by supporting these skills through personalized learning environments.

\section{Discussion}

The idea of personalized learning rests on the foundation that humans learn through experience and by constructing knowledge. It is heavily influenced by a learner's prior experiences and is accomplished via language and social interaction. Personalized learning is not the only way to think about teaching and learning. Moreover, learning will and should take many different forms. Proper instruction, blended instruction, differentiation, proactive supports, real-world connections, and applications are hallmarks of good, sound personalized learning. In general, personalized-learning models seek to adapt to the pace of learning and the instructional strategies, content and activities being used to fit best each learner's strengths, weaknesses, and interests. Personalized 
learning is about giving students control over their learning, differentiating instruction for each child, and providing real-time feedback. Putting a framework together can help with practical personalized learning for all and can be developed as it faces challenges. The framework can help with having a structured common-sense personalized learning instead of a learning system that is being interpreted differently. In conjunction with a well-designed curriculum, instructional practice plays a crucial role in how children learn.

Most of the current personalized learning models/ideas are built on technology integration. For example, while Chen, Lee and Chen (2005) proposed a personalized system that provides learning paths (Nabizadeh, Gonçalves, Gama, Jorge and Rafsanjani, 2020) that can be adapted to various levels of difficulty of course materials (Zou and Xie, 2018) and various abilities of learners (p. 239). Klašnja-Milićević et al. (2011) stated that personalized learning occurs when e-learning systems make deliberate efforts to design educational experiences (Flores, Ari, Inan and ArslanAri, 2012) that fit the needs, goals, talents, motivations, and interests of their learners (p. 885). The term of needs is not specified to clarify what needs of the learner need to be considered for robust personalized learning. Considering the needs of the learner is one of the most common components used in personalized learning. However, only a few studies clarify what needs are mentioned to be considered, such as emotional needs, social needs, learning needs, knowledge needs, etc. Even if we agree on a unified definition with each component commonly agreed on, we need to ensure that each component is well defined.

In the past decades, many methods and systems have been proposed to accommodate students' needs by proposing learning environments that consider personal factors. Learning styles (Çakıroğlu, 2014; Klašnja-Milićević et al., 2011; Latham, Crockett and McLean, 2014) have been among the broadly chosen components in previous studies as a reference for adapting learning. For example, George and Lal (2019) argued that personalized learning is meant to incorporate a learner's varied attributes, including learning style, knowledge level on a subject, preferences, and learner's prior knowledge while they discussed adaptive learning is adapting content according to learner's choice and pace. Chen, Huang, Shih and Chang (2016) brought up the gender component to personalized learning. Furthermore, Atkinson (2006) found that there was a significant difference in learning achievement between male and female students, and among students who used different learning styles (Çakıroğlu, 2014; Klašnja-Milićević et al., 2011; Latham et al., 2014).

Our findings revealed that individualized instruction mostly focuses on special education students or students are limited in way compared to their peers. These students have IEPs (individualized educational plans) mandated by the state to be followed to ensure the schools are accommodating these students' needs. One goal could be to create IEPs for all learners.

Moreover, it seems in education industry terms are quite varied, but when it comes to academia, it is mostly adaptive learning and personalized learning being used interchangeably Rastegarmoghadam and Ziarati (2017); however, mostly adaptive learning is being used when it is technology-enhanced learning. Adaptivity is typically referring to content being adjusted according to prior knowledge (Huang and Shiu, 2012), while 
personalized learning is being used for more broad adjustments according to different needs, interests, and goals of individuals.

Another finding is that adaptive learning is the most used term follows personalized learning. Individualized learning and customized learning, even though they are being used by cooperative, they are not commonly used in research. As shown in Table 4, we have found 56 papers met the minimum quality criteria and were examined in detail; 33 of them use personalized learning, 17 adaptive learning, three individualized instruction, and three customized learning.

However, it seems that also the lack of a commonly identified personalized learning approach is an obstacle. This might be due to the nature of technology involvement; due to the rapid development increase in technology that makes personalized learning an evolving approach. That is fine if we all can agree that it should evolve as technology improves, and we learn more about humans and how human-machine interaction can improve the learning process.

Besides, another obstacle is the researchers and policymakers should show the same interest to personalized learning so the demand and research can align. Educators fear that machines will take over the teaching job if they allow technology to be used for teaching. Kinshuk, Huang, Sampson and Chen (2013) argued that the benefits of technology in education caught the interest of researchers, governments, and funding agencies. Computer systems were funded to help students in the learning process, consequently decreasing teachers' workload. As a result, educational technology research was able to study advanced issues such as intelligent tutoring, simulations, advanced learning management systems, automatic assessment systems, and adaptive systems. Some educators believe that since technology involves big budgets, the interest of policymakers is not due to the interest of improving learning experience (Troussas, Krouska and Sgouropoulou, 2020); their interest is due to the monetary benefit they gain from increased use of technology in education. In addition, Kinshuk et al. (2013) pointed out that practitioners in education could not take advantage of all that research at an equally fast pace, and the implementation lagged severely behind. Researchers need to keep up with the demand of personalized learning. The alignment will help to ensure the practices policy makers discuss are research based efficient approaches that will increase efficiency of learning/teaching.

The progress of the research in personalized learning shows that by technological improvement, personalized learning becomes more embedded with technology and taking advantage of the benefits technology can offer. Some of these advantages are gathering data of learners' emotions by using bio-trackers, which might bring up some privacy concerns.

\section{Limitations}

This study encountered several shortcomings during the review and in its attempt to answer all the research questions. The enormous number of published papers might lead to some missing relevant papers; numerous literature review studies face this problem. Furthermore, the immense effort to construct a search by identifying the keywords is crucial for the search process. The keyword determination method was conducted using a snowballing process to identify the reflections or keywords relevant to this 
study. Overlooking articles by omitting relevant information or keyword combinations is likewise possible due to the limited time frame.

Nevertheless, this study also faces the possible limitation caused by the selection criteria. For example, this study focused on only journal articles and was limited to only documents written in English. Therefore, other pertinent articles that are not written in English and were not published in journals might have not included.

\section{Future research}

Our findings revealed that there is no unified agreement on what components to consider planning a personalized adaptive learning environment. Future research can focus on components included in different personalized adaptive learning systems and the term's definition to build a unified approach and definition. Future studies focusing on what components are being used for each personalized learning approach simultaneously need to acknowledge it as a term that will evolve by time as we learn more about human psychology and develop more technologies. Chatti et al. (2010) and Peng et al. (2019) paper put it all together very well, and Peng et al. (2019) called it a personalized adaptive learning. Future studies can be built on this approach to develop a general framework.

Also, a focus on higher-order thinking skills is not a common theme in the existing literature. This gap can be filled up by focusing on higher-order thinking skills cultivation by supporting these skills through personalized learning environments. Future studies can also focus on adding higher-order thinking skills as an outcome of personalized learning models and seek embedding of virtual reality techniques with considering ethical and privacy concerns.

Furthermore, a in depth study is needed to review current personalized adaptive learning platforms/systems and see if different systems work better for different goals and needs.

\section{Conclusions}

In conclusion, this study found and analyzed 56 relevant studies based on the research protocol. The findings from this study support that adaptive/personalized learning has become a fundamental learning paradigm in the research community of educational technologies. Firstly, the findings are presented as they relate to the R.Q. (Research Question) s; then, the future direction and limitations are discussed. The SLR results show that using personality traits and their identification techniques has an enormously positive influence in adaptive learning environments. This study is related to several significant domains of psychology, education, and computer science. It likewise reveals the integration of personal traits in the adaptive learning environment, which involves many personality traits and identification techniques that can influence learning. Also, it found that there is an increase of interest in two areas that are oriented towards the incorporation and exploration of significant data capabilities in education: Educational Data Mining (EDM) and Learning Analytics (LA) and their respective communities (Papamitsiou and Economides, 2014) which seems to adding another perspective to personalized learning and make it easier modify the learning according individuals.

It seems the personalized learning models gain more attention from governments and policymakers than educators and researchers. We need to focus on the obstacles of 
lack of interest to motivate the educators and researchers, the experts of the field, to voice their concerns and look for solutions to come up with a robust personalized learning model that will satisfy both instructor and learners' expectations. Personalized learning cannot be a solution to learning until it is defined better and developed more thoroughly. Personalized learning for everyone looks different according to the needs and goals of the individual. Ennouamani, Mahani and Akharraz (2020) argued that learners are different in terms of their needs, knowledge, personality, behavior (Pliakos et al., 2019) preferences, learning style, culture, as well as the parameters of the mobile devices that they use. Furthermore, the increasing involvement of the researchers and educators in proposing personalized learning approaches can increase the trust towards the ICT supported personalized learning models.

In this review study, we have answered some critical research questions, including the issues with different terms that have been used for personalized learning, components of personalized learning, and obstacles to the development of personalized learning. We need more research to be done about personalized learning. We also need the involvement of experts in the field, educators, pedagogues, researchers, software engineers, and programmers to create teams to work on the same goal to produce stable, unified, personalized learning systems/models.

Also, some research issues and potential future development directions are discussed. According to the discussions and results, it was found that adaptive/personalized learning systems seem to evolve as technology develops, however, a unified agreement on the components needs to be included in personalized learning models still needed. These components may evolve as we learn more about human-machine interaction and learn to take advantage of the technology to improve learning experiences. We suggest that researchers might use the consolidated terms of this review to guide future metaanalyses of the impact of personalized learning on student learning and performance.

To sum up, this study discusses the potential obstacles to personalized learning and practical solutions for these issues. We also discussed different components used for personalized learning models and how personalized learning evolves as technology develops, and we learn more about human-machine interaction.

\section{Abbreviations}

IEP: Individualized educational plans; PLP: Personalized learning plan; SJR: Scimago Journal Rank; OECD: Organisation for Economic Co-operation and Development; ICT: Information communication technology; SLR: Systematic Literature Review; R.Q.: Research Question; EDM: Educational Data Mining; LA: Learning Analytics

Acknowledgements

Not applicable.

Authors' contributions

Each author contributed evenly to this paper. All authors read and approved the final manuscript.

Funding

Not applicable.

Availability of data and materials

Not applicable.

Competing interests

The authors have no conflict of interest to declare. 
Received: 5 August 2020 Accepted: 13 September 2020

Published online: 23 October 2020

\section{References}

The papers identified for systematic literature review are marked in the references with an asterisk $(*)$

*Aeiad, E., \& Meziane, F. (2019). An adaptable and personalised elearning system applied to computer. Education and Information Technologies, 78, 674-681.

*Afini Normadhi, N. B., Shuib, L., Md Nasir, H. N., Bimba, A., Idris, N., \& Balakrishnan, V. (2019). Identification of personal traits in adaptive learning environment: Systematic literature review. Computers \& Education, 130, 168-190. https://doi.org/10. 1016/j.compedu.2018.11.005

Aroyo, L., Dolog, P., Houben, G.J., Kravcik, M., Naeve, A., Nilsson, M., \& Wild, F. (2006). Interoperability in personalized adaptive learning. Educational Technology \& Society, 9(2), 4-18.

Atkinson, S. (2006). Factors influencing successful achievement in contrasting design and technology activities in higher education. International Journal of Technology and Design Education, 16, 193-213.

Bahçeci, F., \& Gürol, M. (2016). The effect of individualized instruction system on the academic achievement scores of students. Education Research International, 2016, 1-9. https://doi.org/10.1155/2016/7392125.

Barrio, B. L., Miller, D., Hsiao, Y. J., Dunn, M., Petersen, S., Hollingshead, A., \& Banks, S. (2017). Designing culturally responsive and relevant individualized educational programs. Intervention in School and Clinic, 53(2), 114-119. https://doi.org/10. $1177 / 1053451217693364$

*Benhamdi, S., Babouri, A., \& Chiky, R. (2017). Personalized recommender system for e-Learning environment. Education and Information Technologies, 22(4), 1455-1477. https://doi.org/10.1007/s10639-016-9504-y.

Brusilovsky, P., \& Peylo, C. (2003). Adaptive and intelligent web-based educational systems adaptive and intelligent technologies for web-based educational systems. International Journal of Artificial Intelligence in Education, 13, 156-169.

*Çakıroğlu, Ü. (2014). Analyzing the effect of learning styles and study habits of distance learners on learning performances: a case of an introductory programming course. International Review of Research in Open and Distance Learning, 15(4), 161185.

Cavanagh, S. (2014). What is "personalized learning"? Educators seek clarity. Education Week, 34(9), S2-S4.

Chatti, M. A. (2010). Personalization in technology enhanced learning: a social software perspective. Aachen: Shaker Verlag.

*Chatti, M. A., Jarke, M., \& Specht, M. (2010). The 3P learning model. Educational Technology \& Society, 13(4), 74-85.

Chen, C. M., Lee, H. M., \& Chen, Y. H. (2005). Personalized e-learning system using item response theory. Computers \& Education, 44(3), 237-255.

Chen, C. M., Liu, C. Y., \& Chang, M. H. (2006). Personalized curriculum sequencing utilizing modified item response theory for web-based instruction. Expert Systems with Applications, 30(2), 378-396.

Chen, S. Y., Huang, P. R., Shih, Y. C., \& Chang, L. P. (2016). Investigation of multiple human factors in personalized learning Interactive Learning Environments, 24(1), 119-141.

Cheung, W. S., \& Hew, K. F. (2009). A review of research methodologies used in studies on mobile handheld devices in K-12 and higher education settings. Australasian Journal of Educational Technology, 25(2), 153-183.

${ }^{*}$ Chou, C. Y., Lai, K. R., Chao, P. Y., Lan, C. H., \& Chen, T. H. (2015). Negotiation based adaptive learning sequences: combining adaptivity and adaptability. Computers \& Education, 88, 215-226. https://doi.org/10.1016/..compedu.2015.05.007.

Dawson, S., Heathcote, L., \& Poole, G. (2010). Harnessing ICT potential: the adoption and analysis of ICT systems for enhancing the student learning experience. International Journal of Educational Management, 24(2), 116-128.

Dewey, J. (1915). The school and society. Chicago: Chicago Press.

Dewey, J. (1998). Experience and education (60th anniversary edn.). West Lafayette: Kappa Delta.

*Dwivedi, P., \& Bharadwaj, K. K. (2013). Effective trust-aware E-learning recommender system based on learning styles and knowledge levels. Educational Technology \& Society, 16(4), 201-216.

*Ennouamani, S., Mahani, Z., \& Akharraz, L. (2020). A context-aware mobile learning system for adapting learning content and format of presentation: design, validation, and evaluation. Education and Information Technologies. https://doi.org/10. 1007/s10639-020-10149-9

*Erümit, A. K., \& Çetin, I. (2020). Design framework of adaptive intelligent tutoring systems. Education and Information Technologies. https://doi.org/10.1007/s10639-020-10182-8.

*Fatahi, S. (2019). An experimental study on an adaptive e-learning environment based on learner's personality and emotion. Education and Information Technologies, 24(4), 2225-2241. https://doi.org/10.1007/s10639-019-09868-5.

*FitzGerald, E., Kucirkova, N., Jones, A., Cross, S., Ferguson, R., Herodotou, C., ... Scanlon, E. (2018). Dimensions of personalisation in technology-enhanced learning: A framework and implications for design. British Journal of Educational Technology, 49(1), 165-181. https://doi.org/10.1111/bjet.12534

*Flores, R., Ari, F., Inan, F. A., \& Arslan-Ari, I. (2012). The impact of adapting content for students with individual differences. Educational Technology \& Society, 15(3), 251-261.

*Foshee, C. M., Elliott, S. N., \& Atkinson, R. K. (2016). Technology-enhanced learning in college mathematics remediation. British Journal of Educational Technology, 47(5), 893-905. https://doi.org/10.1111/bjet.12285.

*Garcia-Cabot, A., De-Marcos, L., \& Garcia-Lopez, E. (2015). An empirical study on m-learning adaptation: Learning performance and learning contexts. Computers \& Education, 82, 450-459. https://doi.org/10.1016/..compedu.2014.12.007.

*George, G., \& Lal, A. M. (2019). Review of ontology-based recommender systems in e-learning. Computers \& Education, 142(July), 103,642 https://doi.org/10.1016/..compedu.2019.103642.

Göbel, S., Wendel, V., Ritter, C., \& Steinmetz, R. (2010). Personalized, adaptive digital educational games using narrative gamebased learning objects. In International conference on technologies for E-learning and digital entertainment, (pp. 438-445). Berlin. Springer.

Gómez, S., Zervas, P., Sampson, D. G., \& Fabregat, R. (2014). Context-aware adaptive and personalized mobile learning delivery supported by UoLmP. Journal of King Saud University - Computer and Information Sciences, 26(1), 47-61. https://doi.org/10. 1016/j.jksuci.2013.10.008 
${ }^{*}$ Griff, E. R., \& Matter, S. F. (2013). Evaluation of an adaptive online learning system. British Journal of Educational Technology, 44(1), 170-176. https://doi.org/10.1111/j.1467-8535.2012.01300.x.

*Hooshyar, D., Ahmad, R. B., Yousefi, M., Yusop, F. D., \& Horng, S. J. (2015). A flowchart-based intelligent tutoring system for improving problem-solving skills of novice programmers. Journal of Computer Assisted Learning, 31(4), 345-361. https:// doi.org/10.1111/jcal.12099.

*Hsieh, C. W., \& Chen, S. Y. (2016). A cognitive style perspective to handheld devices: customization vs. personalization. International Review of Research in Open and Distance Learning, 17(1), 1-22. https://doi.org/10.19173/irrodl.v17i1.2168.

*Huang, S. L., \& Shiu, J. H. (2012). A user-centric adaptive learning system for e-learning 2.0. Educational Technology \& Society, 15(3), 214-225.

Huang, Y. M., Liang, T. H., Su, Y. N., \& Chen, N. S. (2012). Empowering personalized learning with an interactive e-book learning system for elementary school students. Educational Technology Research and Development, 60(4), $703-722$. https://doi.org/10.1007/s11423-012-9237-6.

*Hwang, G. J., Sung, H. Y., Hung, C. M., \& Huang, I. (2013). A learning style perspective to investigate the necessity of developing adaptive learning systems. Educational Technology \& Society, 16(2), 188-197.

*Jung, E., Kim, D., Yoon, M., Park, S., \& Oakley, B. (2019). The influence of instructional design on learner control, sense of achievement, and perceived effectiveness in a supersize MOOC course. Computers \& Education, 128(October 2018), $377-$ 388 https://doi.org/10.1016/j.compedu.2018.10.001

*Junokas, M. J., Lindgren, R., Kang, J., \& Morphew, J. W. (2018). Enhancing multimodal learning through personalized gesture recognition. Journal of Computer Assisted Learning, 34(4), 350-357. https://doi.org/10.1111/jcal.12262.

*Kinshuk (2012). Guest editorial: personalized learning. Educational Technology Research and Development, 60(4), $561-562$. https://doi.org/10.1007/s11423-012-9248-3.

*Kinshuk, Huang, H.-W., Sampson, D., \& Chen, N.-S. (2013). Trends in educational technology through the lens of the highly cited articles published in the Journal of Educational Technology and Society. Educational Technology \& Society, 16(2), 320 .

*Klašnja-Milićević, A., Vesin, B., Ivanović, M., \& Budimac, Z. (2011). E-Learning personalization based on hybrid recommendation strategy and learning style identification. Computers \& Education, 56(3), 885-899. https://doi.org/10. 1016/j.compedu.2010.11.001.

*Ko, C. C., Chiang, C. H., Lin, Y. L., \& Chen, M. C. (2011). An individualized e-Reading system developed based on multirepresentations approach. Educational Technology \& Society, 14(4), 88-98.

*Latham, A., Crockett, K., \& McLean, D. (2014). An adaptation algorithm for an intelligent natural language tutoring system. Computers \& Education, 71, 97-110. https://doi.org/10.1016/j.compedu.2013.09.014.

*Lee, D., Huh, Y., Lin, C. Y., \& Reigeluth, C. M. (2018). Technology functions for personalized learning in learner-centered schools. Educational Technology Research and Development, 6(5), 1269-1302. https://doi.org/10.1007/s11423-018-9615-9.

*Lin, C. F., Yeh, Y. C., Hung, Y. H., \& Chang, R. I. (2013). Data mining for providing a personalized learning path in creativity: an application of decision trees. Computers \& Education, 68, 199-210. https://doi.org/10.1016/j.compedu.2013.05.009.

*Liu, M., McKelroy, E., Corliss, S. B., \& Carrigan, J. (2017). Investigating the effect of an adaptive learning intervention on students' learning. Educational Technology Research and Development, 65(6), 1605-1625. https://doi.org/10.1007/s11423017-9542-1.

*Liu, M.-T., \& Yu, P.-T. (2011). International forum of educational technology \&amp; Society aberrant learning achievement detection based on person-fit statistics in personalized e-learning systems. Journal of Educational Technology \& Society 14(1), 107-120. https://doi.org/10.2307/jeductechsoci.14.1.107

*Lo, J. J., Chan, Y. C., \& Yeh, S. W. (2012). Designing an adaptive web-based learning system based on students' cognitive styles identified online. Computers \& Education, 58(1), 209-222. https://doi.org/10.1016/j.compedu.2011.08.018.

Lockspeiser, T. M., \& Kaul, P. (2016). Using individualized learning plans to facilitate learner-centered teaching. Journal of Pediatric and Adolescent Gynecology, 29(3), 214-217. https://doi.org/10.1016/j.jpag.2015.10.020.

*Lu, C., Chang, M., Kinshuk, Huang, E., \& Chen, C. W. (2014). Context-aware mobile role-playing game for learning. Lecture Notes in Educational Technology, 17(9783642382901), 131-146. https://doi.org/10.1007/978-3-642-38291-8_8.

McCombs, B. L., \& Whisler, J. S. (1997). The learner-centered classroom and school: Strategies for increasing student motivation and achievement, (1st ed.). San Francisco: Jossey-Bass.

Miliband, D. (2006). Choice and voice in personalised learning. In OECD (Ed.), Schooling for tomorrow: personalising education, (pp. 21-30). Paris: OECD Publishing.

*Nabizadeh, A. H., Gonçalves, D., Gama, S., Jorge, J., \& Rafsanjani, H. N. (2020). Adaptive learning path recommender approach using auxiliary learning objects. Computers \& Education, 147(November 2019), 103777 https://doi.org/10.1016/j.compedu. 2019.103777

*Nedungadi, P., \& Raman, R. (2012). A new approach to personalization: Integrating e-learning and m-learning. Educational Technology Research and Development, 60(4), 659-678. https://doi.org/10.1007/s11423-012-9250-9.

*Niknam, M., \& Thulasiraman, P. (2020). LPR: a bio-inspired intelligent learning path recommendation system based on meaningful learning theory. Education and Information Technologies. https://doi.org/10.1007/s10639-020-10133-3.

Okoli, C. (2015). A guide to conducting a standalone systematic literature review. Communications of the Association for Information Systems, 37(1), 879-910. https://doi.org/10.17705/1 cais.03743.

Organisation for Economic Co-operation and Development (OECD). (2006). Are students ready for a technology-rich world? What PISA studies tell us. Retrieved from http://www.oecd.org

Ormrod, J. E. (2011). Human learning. London: Pearson Higher.

Papamitsiou, Z., \& Economides, A. A. (2014). Learning analytics and educational data mining in practice: a systemic literature review of empirical evidence. Educational Technology \& Society, 17(4), 49-64.

Peng, H., Ma, S., \& Spector, J. M. (2019). Personalized adaptive learning: an emerging pedagogical approach enabled by a smart learning environment. Lecture Notes in Educational Technology, 171-176. https://doi.org/10.1007/978-981-13-69087_24.

*Pliakos, K., Joo, S. H., Park, J. Y., Cornillie, F., Vens, C., \& Van den Noortgate, W. (2019). Integrating machine learning into item response theory for addressing the cold start problem in adaptive learning systems. Computers \& Education, 137(April), 91-103. https://doi.org/10.1016/j.compedu.2019.04.009. 
*Pontual Falcão, T., e Peres, F. M. A., Sales de Morais, D. C., \& da Silva Oliveira, G. (2018). Participatory methodologies to promote student engagement in the development of educational digital games. Computers \& Education, 116, 161-175. https://doi.org/10.1016/j.compedu.2017.09.006

*Ramos De Melo, F., Flôres, E. L., Diniz De Carvalho, S., Gonçalves De Teixeira, R. A., Batista Loja, L. F., \& De Sousa Gomide, R. (2014). Computational organization of didactic contents for personalized virtual learning environments. Computers \& Education, 79, 126-137. https://doi.org/10.1016/..compedu.2014.07.012.

* Rastegarmoghadam, M., \& Ziarati, K. (2017). Improved modeling of intelligent tutoring systems using ant colony optimization. Education and Information Technologies, 22(3), 1067-1087. https://doi.org/10.1007/s10639-0169472-2.

Reisman, S. (2014). The future of online instruction, Part 2. Computer, 47(6), 82-84. https://doi.org/10.1109/MC.2014.168.

Sampson, D., Karagiannidis, C., \& Kinshuk (2002). Personalised learning: educational, technological and standardisation perspective. Interactive Educational Multimedia: IEM, 4(4), 24-39.

*Scheiter, K., Schubert, C., Schüler, A., Schmidt, H., Zimmermann, G., Wassermann, B., ... Eder, T. (2019). Adaptive multimedia: using gaze-contingent instructional guidance to provide personalized processing support. Computers \& Education, 139, 31-47. https://doi.org/10.1016/..compedu.2019.05.005.

*Schmid, R., \& Petko, D. (2019). Does the use of educational technology in personalized learning environments correlate with self-reported digital skills and beliefs of secondary-school students? Computers \& Education, 136(March), 75-86. https:// doi.org/10.1016/j.compedu.2019.03.006.

Sharples, M. (2000). The design of personal mobile technologies for lifelong learning. Computers \& Education, 34(3-4), 177193. https://doi.org/10.1016/s0360-1315(99)00044-5.

*Shute, V. J., \& Rahimi, S. (2017). Review of computer-based assessment for learning in elementary and secondary education. Journal of Computer Assisted Learning, 33(1), 1-19. https://doi.org/10.1111/jcal.12172.

*Somyürek, S. (2015). The new trends in adaptive educational hypermedia systems. International Review of Research in Open and Distance Learning, 16(1), 221-241. https://doi.org/10.19173/irrodl.v16i1.1946.

*Spector, J. M. (2013). Emerging educational technologies and research directions. Educational Technology \& Society, 16(2), 21-30.

Spector, J. M. (2014). Conceptualizing the emerging field of smart learning environments. Smart Learning Environments, 1, 2. https://doi.org/10.1186/s40561-014-0002-7.

Spector, J. M. (2015). Foundations of educational technology: integrative approaches and interdisciplinary perspectives, (2nd ed.). New York: Routledge.

Spector, J. M. (2018). The potential of smart technologies for learning and instruction. International Journal of Smart Technology \& Learning, 1(1), 21-32. https://doi.org/10.1504/IJSMARTTL.2016.078163.

Sungkur, R. K., Antoaroo, M. A., \& Beeharry, A. (2016). Eye tracking system for enhanced learning experiences. Education and Information Technologies, 21(6), 1785-1806. https://doi.org/10.1007/s10639-015-9418-0.

*Tomberg, V., Laanpere, M., Ley, T., \& Normak, P. (2013). Sustaining teacher control in a blog-based personal learning environment. International Review of Research in Open and Distance Learning, 14(3), 109-133 https://doi.org/10.19173/ irrodl.v14i3.1397.

*Troussas, C., Krouska, A., \& Sgouropoulou, C. (2020). Collaboration and fuzzy-modeled personalization for mobile game-based learning in higher education. Computers \& Education, 144(September 2019), 103698 https://doi.org/10.1016/j.compedu. 2019.103698

Truong, H. M. (2016). Integrating learning styles and adaptive e-learning system: current developments, problems, and opportunities. Computers in Human Behavior, 55, 1185-1193 https://doi.org/10.1016/..chb.2015.02.014.

Tseng, S.-S., Su, J.-M., Hwang, G.-J., Hwang, G.-H., Tsai, C.-C., \& Tsai, C.-J. (2008). An object- oriented course framework for developing adaptive learning systems. Educational Technology \& Society, 11(2), 171-191.

U.S. Department of Education (2010). Transforming American education: Learning powered by technology. Washington, DC: Office of Educational Technology.

U.S. Department of Education, Office of Educational Technology (2017). Reimagining the role of technology in education: 2017 national education technology plan update. Available at: https://tech.ed.gov/files/2017/01/NETP17.pdf.

*Wang, Y. H., \& Liao, H. C. (2011). Adaptive learning for ESL based on computation. British Journal of Educational Technology, 42(1), 66-87. https://doi.org/10.1111/j.1467-8535.2009.00981.x.

*Xie, H., Chu, H. C., Hwang, G. J., \& Wang, C. C. (2019). Trends and development in technology-enhanced adaptive/ personalized learning: a systematic review of journal publications from 2007 to 2017. Computers \& Education, 140(June), 103599 https://doi.org/10.1016/j.compedu.2019.103599.

Yang, T. C., Hwang, G. J., \& Yang, S. J. H. (2013). Development of an adaptive learning system with multiple perspectives based on students' learning styles and cognitive styles. Educational Technology \& Society, 16(4), 185-200.

*Zou, D., \& Xie, H. (2018). Personalized word-learning based on technique feature analysis and learning analytics. Educational Technology \& Society, 21(2), 233-244.

\section{Publisher's Note}

Springer Nature remains neutral with regard to jurisdictional claims in published maps and institutional affiliations. 